Short communication

\title{
Club drug use among college students
}

\author{
Jeffrey S. Simons ${ }^{\mathrm{a}, *}$, Raluca M. Gaher ${ }^{\mathrm{a}}$, Christopher J. Correia ${ }^{\mathrm{b}}$, \\ Jacqueline A. Bush ${ }^{\mathrm{a}}$ \\ ${ }^{a}$ University of South Dakota, United States \\ ${ }^{\mathrm{b}}$ Auburn University, United States
}

\begin{abstract}
This study examined prevalence and frequency of "club" drug use among college students $(N=831)$ and associations with marijuana and alcohol use, sensation seeking, and positive and negative affectivity. Eighteen percent $(n=146)$ of the sample had used club drugs at least once in their lifetime. Results of a logistic regression indicated that club drug use was positively associated with marijuana use, negative affectivity, and female gender. Among those who had tried club drugs in their lifetime, $42 \%$ reported no past year use and $22.6 \%$ reported using $7-12$ times or more in the past year. Regression analysis examined associations between 12-month use frequency and the predictors among those who had tried club drugs. Results indicated that sensation seeking and marijuana use were positively associated with use frequency.
\end{abstract}

(C) 2005 Elsevier Ltd. All rights reserved.

Keywords: Drug usage; Marijuana; Methylenedioxymethamphetamine; Methamphetamine; Personality; College students

\section{Club drug use among college students}

Club drugs are a loosely defined category of drugs from different classes (e.g., stimulants, hallucinogens) grouped due to their use at dance clubs and raves. Common

\footnotetext{
* Corresponding author. 414 East Clark St., Department of Psychology, University of South Dakota, Vermillion, South Dakota 57069. Tel.: +1 605677 5353; fax: +1 6056776604 .

E-mail address: jsimons@usd.edu (J.S. Simons).
} 
examples include ecstasy (MDMA), methamphetamine, and ketamine (National Institute on Drug Abuse, 2004). Approximately 15\% of young adults ages 18-25 report lifetime use of MDMA and 24\% report use of MDMA or some other hallucinogen (Substance Abuse and Mental Health Services Administration [SAMHSA], 2003). Approximately 11\% of young adults report lifetime use of methamphetamine or other illicit stimulants (SAMHSA, 2003). Though the lifetime use prevalence of club drugs is relatively low, and current use markedly lower (e.g., $\sim 1 \%$ report past month and $\sim 6 \%$ past year ecstasy use; SAMHSA, 2003), use of these drugs can have significant negative consequences (American Psychiatric Association, 2000).

Sensation seeking is a temperament dimension characterized by the tendency to seek novel and stimulating experiences (Zuckerman, 1994). Sensation seeking has been linked to the use of ecstasy and other drugs (Low \& Gendaszek, 2002; Wills, Windle, \& Cleary, 1998). Positive and negative affectivity have been linked to substance use (Wills, Sandy, Shinar, \& Yaeger, 1999). Negative affectivity has been associated with higher rates of use (Wills et al., 1999). Positive affectivity has exhibited negative associations with use in some studies (Wills et al., 1999). However, associations have been somewhat inconsistent across studies (Cooper, Frone, Russell, \& Mudar, 1995).

Significant associations between club drug use and marijuana and alcohol use have been observed in high school populations (Yacoubian, Green, \& Peters, 2003). Given the high prevalence of alcohol use in college populations, it is unlikely that it is a relevant predictor of club drug use. However, marijuana use is less prevalent and may thus predict club drug use in this population.

The current study examined lifetime and past year use of club drugs among college students. Sensation seeking and negative affectivity were hypothesized to be positively associated with use, while positive affectivity was hypothesized to be negatively associated with use. Male gender and marijuana use was expected to be positively associated with club drug use.

\subsection{Participants and procedure}

The sample consisted of 831 college students at two state universities participating in research for partial fulfillment of course requirements. Approximately $70 \%$ of the sample were women. The mean age was $20.20, S D=2.81$. Eighty-nine percent were White, $7 \%$ Black, 2\% Asian/Pacific Islander, and 3\% other races. A subset of this data was used in two previous studies (Simons \& Gaher, 2004; Simons, Gaher, Correia, Hansen, \& Christopher, in press).

\subsection{Measures}

Club drugs, marijuana, and alcohol use frequency in the past 12 months were assessed by 9-point rating scales $(0=$ none at all, $8=$ more than daily). The club drug item was worded as “...'club drugs' (e.g., crystal meth, ecstasy (MDMA), MDA, Special K (Ketamine), amphetamines, speed)." Lifetime use was assessed by an 8-point rating scale $(0=$ never used, 
$7=$ more than 300 days). Sensation seeking was assessed by a 16-item version of Zuckerman's sensation seeking scale (Donohew, Zimmerman, Cupp, Novak, Colon, \& Abell, 2000). Scale items are rated on a 5-point scale $(1=$ Disagree a lot, 5=Agree a lot; $\alpha=.81)$. Positive and negative affectivity were assessed by the General Temperament Survey (Clark \& Watson, 1990). The positive affectivity scale is 27 items $(\alpha=.84)$ (Watson, Clark, McIntyre, \& Hamaker, 1992). A 20 -item version of the negative affectivity scale $(\alpha=.95)$ was used. Both measures used a 4-point scale $(1=$ false, $4=$ true, Stice, Myers, \& Brown, 1998).

\section{Results}

\subsection{Descriptive statistics}

Eighteen percent $(n=146)$ reported using club drugs in their lifetime and $11 \%(n=89)$ reported use in the past 12 months. Among those who had tried club drugs, mean lifetime use was 3-11 days (rating scale $M=2.45, S D=1.33$ ). Mean use in the past 12 months was $1-3$ times a year (rating scale $M=1.28, S D=1.57$ ). Forty-two percent of those reporting some use in lifetime reported no use in the past year, 22.6\% reported using 7-12 times or more, and $13 \%$ reported using weekly or more. In contrast, in the past 12 months, 37\% $(n=309)$ reported marijuana use, and $88 \%(n=735)$ reported alcohol use. Correlations are presented in Table 1.

\subsection{Use initiation}

We included all participants $(N=831)$ in a logistic regression with a dichotomous lifetime use indicator as the criterion and gender $(1=$ male, $0=$ female $)$, lifetime marijuana and alcohol use, university ( $1=$ Sample $1,0=$ Sample 2$)$, positive and negative affectivity, and sensation

Table 1

Correlations among variables

\begin{tabular}{|c|c|c|c|c|c|c|c|c|}
\hline & 1. & 2. & 3. & 4. & 5. & 6. & 7. & 8. \\
\hline 1. University & & .10 & .20 & -.15 & .11 & .00 & -.02 & .00 \\
\hline 2. Gender & .02 & & .23 & .20 & .08 & -.03 & .04 & .29 \\
\hline 3. Marijuana & .00 & .15 & & .31 & .37 & -.04 & -.03 & .27 \\
\hline 4. Alcohol & .07 & .12 & .57 & & .18 & .06 & -.02 & .31 \\
\hline 5. Club drugs & -.09 & .04 & .58 & .31 & & .07 & .04 & .30 \\
\hline 6. Neg. affectivity & -.02 & -.07 & .05 & .06 & .10 & & -.26 & -.12 \\
\hline 7. Pos. affectivity & -.05 & -.05 & -.10 & -.05 & -.06 & -.18 & & .28 \\
\hline 8. Sensation seeking & .08 & .21 & .32 & .38 & .20 & .06 & .20 & \\
\hline
\end{tabular}

Note: Full sample $(N=831)$ correlations are below the diagonal., $r \geq|.07|, p<.05 ; r \geq|.10|, p<.01$. Marijuana, alcohol and club drug use refer to lifetime use frequency. Lifetime use (i.e., ever tried) sample $(N=146)$ is above the diagonal, $r \geq|.18|, p<.05, r \geq|.23|, p<.01$. Marijuana, alcohol and club drug use refer to 12-month use frequency. University is coded $1=$ Sample $1,0=$ Sample 2 . Gender is coded $1=$ male, $0=$ female. Neg. $=$ negative, pos. $=$ positive. 
seeking as explanatory variables. The full model was significant $\left(\chi^{2}(7)=345.91, p<.0001\right)$. Lifetime marijuana use $(\mathrm{O} . \mathrm{R} .=2.70, p<.001)$ and negative affectivity $(\mathrm{O} . \mathrm{R} .=1.02, p=.018)$ were positively associated with club drug use. Sample 1 participants were less likely to have tried club drugs $(\mathrm{O} . \mathrm{R} .=0.44, p=.002)$. Contrary to hypothesis, men were less likely to have tried club drugs (O.R. $=0.42, p=.003)$. Sensation seeking $(\mathrm{O} . \mathrm{R} .=1.02, p=.285)$ and positive affectivity $(\mathrm{O} . \mathrm{R} .=1.0, p=.317)$ were not associated with use initiation.

\subsection{Use frequency}

For the use frequency analysis, only participants reporting having tried club drugs at least once were included $(n=146)$. At Step 1, use frequency was regressed on gender, 12-month marijuana and alcohol use frequency, and university, $F(4,141)=5.82, p=.0002, R^{2}=.14$. Only marijuana use was a significant predictor. At Step 2, positive and negative affectivity and sensation seeking were entered, $F(3,183)=3.15, p=.027, \Delta R^{2}=.06$; Full model $F(7$, $\left.138)=4.83, p=.0001, R^{2}=.20\right)$. Only marijuana use and sensation seeking were significant predictors (see Table 2). The effect size for the temperament terms was $f^{2}=.07$, a small to medium effect.

\section{Discussion}

Lifetime marijuana use and negative affectivity were positively associated with club drug use initiation. Contrary to hypothesis, men were less likely to have tried club drugs. Positive

Table 2

Regression analysis for 12-month club drug use frequency

\begin{tabular}{lrrrr}
\hline \multicolumn{1}{c}{$B$} & SE $B$ & $\beta$ & $p$-value \\
\hline Step 1 & & & & \\
University & 0.18 & 0.27 & .06 & .497 \\
Gender & -0.06 & 0.27 & -.02 & .813 \\
Marijuana use & 0.19 & 0.05 & .33 & $<.001$ \\
Alcohol use & 0.10 & 0.09 & .09 & .306 \\
& & & & \\
Step 2 & & & .06 & .483 \\
University & 0.19 & 0.26 & -.07 & .412 \\
Gender & -0.22 & 0.27 & .30 & .001 \\
Marijuana use & 0.17 & 0.05 & .03 & .767 \\
Alcohol use & 0.03 & 0.09 & .12 & .143 \\
Neg. affectivity & 0.01 & 0.01 & .02 & .805 \\
Pos. affectivity & 0.00 & 0.01 & .24 & .008 \\
Sensation seeking & -2.75 & 0.01 & \\
\hline
\end{tabular}

Note. $N=146$. Step $1 F(4,141)=5.82, p=.0002, R^{2}=.14$; Step $2 F(3,138)=3.15, p=.027, \Delta R^{2}=.06$; Full model $F(7,138)=4.83, p=.0001, R^{2}=.20$. University is coded $1=$ Sample $1,0=$ Sample 2 . Gender is coded $1=$ male, $0=$ female. Neg. $=$ negative, pos. $=$ positive . 
affectivity and sensation seeking were not associated with club drug use initiation. Among participants who had tried club drugs at least once, marijuana use frequency and sensation seeking were significant predictors of club drug use frequency.

Consistent with previous research, the results indicate that marijuana use is positively associated with club drug use (Yacoubian et al., 2003). This does not suggest that people who use marijuana will progress to use club drugs. The associations simply indicate that people who use club drugs are more likely to have also tried marijuana, and that relative to infrequent marijuana users, individuals who use marijuana at higher rates are more likely to use club drugs at higher rates. Only a minority of people who use marijuana progress to use other drugs (Glantz, Weinberg, Miner, \& Colliver, 1999). In the current sample, 33\% of those who had tried marijuana also tried club drugs.

The pattern of results suggests different relationships between the temperament variables and use initiation and use frequency. Specifically, use initiation was positively associated with negative affectivity while frequency of use was positively associated with sensation seeking. The results indicate that temperament variables that have demonstrated associations with other drugs in previous research are also relevant to the study of club drugs and deserve further investigation.

In summary, club drug use among college students is relatively prevalent. Results of this study indicate positive associations between club drug use and negative affect, sensation seeking, and marijuana use. Further research is needed to examine predictors of negative consequences associated with club drug use.

\section{Acknowledgement}

This research was supported in part by a National Institute on Drug Abuse Grant DA 15066 to Jeffrey S. Simons.

\section{References}

American Psychiatric Association. (2000). Diagnostic and statistical manual of mental disorders. Washington DC: American Psychiatric Association, (4th edition, text revision).

Clark, L. A., \& Watson, D. (1990). The general temperament survey. Iowa City, IA: University of Iowa, Unpublished manuscript.

Cooper, M. L., Frone, M. R., Russell, M., \& Mudar, P. (1995). Drinking to regulate positive and negative emotions: A motivational model of alcohol use. Journal of Personality and Social Psychology, 69, 990-1005.

Donohew, L., Zimmerman, R., Cupp, P. S., Novak, S., Colon, S., \& Abell, R. (2000). Sensation seeking, impulsive decision making, and risky sex: Implications for risk-taking and design of interventions. Personality and Individual Differences, 28, 1079-1091.

Glantz, M. D., Weinberg, N. Z., Miner, L. L., \& Colliver, J. D. (1999). The etiology of drug abuse: Mapping the paths. In M. D. Glantz, \& C. R. Hartel (Eds.), Drug abuse: Origins and interventions. Washington, DC: American Psychological Association.

Low, K. G., \& Gendaszek, A. E. (2002). Illicit use of psychostimulants among college students: A preliminary study. Psychology, Health and Medicine, 7, 283-287. 
National Institute on Drug Abuse. (2004). NIDA community drug alert bulletin-club drugs. http://165.112.78.61/ ClubAlert/ClubdrugAlert.html, Retrieved 9/13/2004.

Simons, J. S., \& Gaher, R. M. (2004). The distress tolerance scale: Development and validation of a self-report measure. Manuscript submitted for publication.

Simons, J.S., Gaher, R.M., Correia, C.J., Hansen, C.L., and Christopher, M.S. (in press). An affective-motivational model of marijuana and alcohol problems among college students. Psychology of Addictive Behaviors.

Stice, E., Myers, M. G., \& Brown, S. A. (1998). A longitudinal grouping analysis of adolescent substance use escalation and de-escalation. Psychology of Addictive Behaviors, 12, 14-27.

Substance Abuse and Mental Health Services Administration [SAMHSA]. (2003). Results from the 2002 national survey on drug use and health: National findings (office of applied studies, nhsda series h-22, dhhs publication no. Sma 03-3836). Rockville, MD.

Watson, D., Clark, L. A., McIntyre, C. W., \& Hamaker, S. (1992). Affect, personality, and social activity. Journal of Personality and Social Psychology, 63, 1011-1025.

Wills, T. A., Sandy, J. M., Shinar, O., \& Yaeger, A. (1999). Contributions of positive and negative affect to adolescent substance use: Test of a bidimensional model in a longitudinal study. Psychology of Addictive Behaviors, 13, 327-338.

Wills, T. A., Windle, M., \& Cleary, S. D. (1998). Temperament and novelty seeking in adolescent substance use: Convergence of dimensions of temperament with constructs from Cloninger's theory. Journal of Personality and Social Psychology, 74, 387-406.

Yacoubian, G. S. J., Green, M. K., \& Peters, R. J. (2003). Identifying the prevalence and correlates of ecstasy and other club drug (eocd) use among high school seniors. Journal of Ethnicity in Substance Abuse, 2, 53-66.

Zuckerman, M. (1994). Behavioral expressions and biosocial bases of sensation seeking. Cambridge, UK: Cambridge University Press. 